ROSSANA BRUM LEQUeS

\title{
O CONSENTIMENTO DO OFENDIDO COMO EXCLUDENTE DO TIPO NO DIREITO PENAL BRASILEIRO
}

\author{
DisSERTAÇÃO DE MESTRAdO
}

Orientador: Professor Titular Dr. Vicente Greco Filho

Universidade de São Paulo

Faculdade de Direito

São Paulo, 2014 


\section{RESUMO}

A presente pesquisa objetiva identificar a natureza jurídica do instituto do consentimento do ofendido para o direito penal brasileiro atual, evidenciando o papel da vítima. Para tanto, inicia-se a pesquisa com uma análise sobre o ofendido, estabelecendo sua evolução histórica, seu conceito atual, bem como os conceitos de vitimologia e vitimodogmática. Logo, aborda-se o consentimento propriamente dito, determinando seu histórico, seu conceito, seu objeto (bem jurídico disponível), seus requisitos e diferenças em relação à autocolocação da vítima em risco. Em seguida, verifica-se o estado atual da questão da natureza jurídica do consentimento. Parte-se da legislação brasileira e do entendimento doutrinário atual. Em razão da predominância do entendimento pela causa de justificação, os fundamentos histórico dogmáticos do conceito material de antijuridicidade são verificados. Ainda no campo da análise da natureza jurídica, fundamental a análise da questão da tipicidade (formal e substancial) - pressuposto da antijuridicidade. Assim, analisa-se o consentimento do ofendido como causa de exclusão da tipicidade material. Tendo em vista a teoria unitária, busca-se afastar a diferenciação entre o consentimento e o acordo. Na sequência, trata-se do direito comparado. Assim, torna-se possível a análise do consentimento do ofendido no direito penal brasileiro, tendo em vista a legislação penal em vigor.

PALAVRAS-CHAVE: Consentimento do ofendido. Vitimologia. Vitimodogmática. Liberdade de ação. Tipicidade substancial. 


\begin{abstract}
This paper aims to identify the legal institute of the need for the offended person's consent for the current Brazilian criminal law, highlighting the role of the victim. To this effect, the study begins with an analysis of victims' rights, establishing their historical evolution, the current concept, as well as the concepts of victimology and victim dogmatism (a branch that studies the behavior of crime victims and their contribution to the occurrence of the event, as well as the repercussion of that participation on setting the penalty imposed on the perpetrator). Then it examines consent itself, determining its history, concept, object (alienable rights), the requirements and differences in relation to the victim's self-exposure to risk. Next it describes the current state of the legal nature of the consent question based on Brazilian legislation and the interpretation of legal scholars. Because of the predominant position regarding cause for justification, dogmatic historical foundations of the material concept of material illegality are addressed. Still in the field of the legal nature, it is fundamental to analyze the question of classification of the crime (formal and substantive), which is a presupposition for illegality. Therefore, consent of the offended person is analyzed as cause to exclude the classification of the act as a crime. Based on unitary theory, I argue against the distinction between consent and concurrence. Finally, the matter is examined from the perspective of comparative law, to analyze the issue of victim's consent in current Brazilian criminal law.
\end{abstract}

KEYWORDS: Consent of the victim. Victimology. Victim dogmatism. Freedom of action. Substantive offense. 


\section{INTRODUÇÃO}

A presente pesquisa objetiva identificar a natureza jurídica do instituto do consentimento do ofendido para o direito penal brasileiro vigente, à luz da vitimologia e da vitimodogmática. O assunto é pouco discutido, e embora não seja um tema novo, consiste em um grande desafio.

Assim, entende-se o consentimento do ofendido como a maneira deste expressar a sua vontade ao autorizar o agente à prática da conduta formalmente descrita no tipo incriminador.

De forma resumida, pode-se afirmar que existem, hodiernamente, três principais correntes doutrinárias sobre os efeitos do referido instituto. A primeira o considera como causa de justificação, a segunda preceitua que o consentimento sempre excluirá o tipo, considerado como um critério de imputação objetiva, e a terceira corrente abarca os dois posicionamentos, cujo enquadramento dependerá da construção típica em análise.

No Brasil, nota-se que é escassa a aplicação do consentimento, independentemente dos efeitos conferidos ao instituto, restando o papel da vítima praticamente esquecido, tanto no âmbito legislativo, quanto jurisdicional.

De tal modo, inicia-se a pesquisa com uma análise sobre o ofendido, estabelecendo sua evolução histórica, seu conceito atual, bem como os conceitos de vitimologia e vitimodogmática. Tais noções são fundamentais, já que o instituto em comento compreende o ofendido.

Logo, aborda-se o consentimento propriamente dito, determinando seu histórico, seu conceito, seu objeto (bem jurídico disponível), seus requisitos e diferenças em relação à autocolocação da vítima em risco.

Em seguida, verifica-se o estado atual da questão da natureza jurídica do consentimento. Para tanto, a legislação brasileira é analisada, bem como o entendimento doutrinário atual. Em razão da predominância do entendimento pela causa de justificação, os fundamentos histórico dogmáticos do conceito material de antijuridicidade são verificados.

Ainda no campo da análise da natureza jurídica, fundamental a análise da questão da tipicidade (formal e substancial) - pressuposto da antijuridicidade, de modo a 
possibilitar uma compreensão adequada e profunda sobre o tema. Nesse momento, constata-se o sentido polissêmico do termo tipo, o conceito de tipicidade e a evolução da construção dogmática com a tipicidade substancial. Assim, analisa-se o consentimento do ofendido como causa de exclusão da tipicidade material. Tendo em vista a teoria unitária, busca-se afastar a diferenciação entre o consentimento e o acordo.

Na sequência, importante tratar sobre o direito comparado. Desse modo, merece análise o tradicional direito italiano, origem da grande maioria dos nossos institutos. Também o direito português, dado o intenso intercâmbio entre a doutrina, a qual é certamente facilitada pela língua comum. Por fim, o direito alemão, em que vêm sendo desenvolvidas as correntes mais modernas, bem como o referencial teórico do presente trabalho.

Assim, torna-se possível a análise do consentimento do ofendido no direito penal brasileiro, tendo em vista a legislação penal em vigor. 


\section{CONCLUSÕES}

Após o desenvolvimento do presente estudo, algumas conclusões podem ser lançadas a título de condensação das ideias expostas:

1 - A vitimologia é o ramo das ciências criminais atrelado à criminologia responsável pelo estudo das vítimas.

2 - A vítima é o indivíduo que sofre a conduta do agente criminoso. Suas diferentes espécies possibilitam uma tipificação mais adequada, contribuindo para a compreensão do caso concreto.

3 - O papel exercido pela vítima (vitimodogmática) não pode ser desconsiderado, tendo em vista a sua participação na conduta criminosa. Visa-se com isso aplicar de forma mais racional a pena, proporcionando soluções mais justas para os conflitos, o que possibilita inclusive a exoneração da responsabilidade do agente (e não apenas a atenuação de sua pena).

4 - O nosso ordenamento jurídico possui preocupação muito tímida com a vítima. Deve-se, portanto, buscar políticas criminais legislativas e judiciais que considerem os postulados vitimológicos e vitimodogmáticos, especialmente considerado o consentimento do ofendido no presente trabalho.

5 - O consentimento do ofendido consiste na maneira deste expressar sua vontade ao autorizar o agente à prática da conduta formalmente descrita no tipo incriminador.

6 - Tendo em vista a sua natureza jurídica (teoria unitária), o consentimento não deve ser diferenciado do acordo e sempre excluirá o tipo, ainda que o dissenso não seja um elemento do tipo penal em análise.

7 - O seu principal fundamento consiste no exercício do poder de autonomia (princípio da dignidade humana), nos termos do art. $1^{\circ}$, inciso III, da Constituição Federal, bem como da liberdade de ação, conforme art. $5^{\circ}$ da Constituição Federal. 
8 - Para tanto, faz-se necessário que o seu objeto seja um bem jurídico disponível. Logo, os bens jurídicos coletivos não são passíveis de consentimento. Quanto aos individuais, devese considerar o caso concreto, observados os critérios acima assinalados.

9 - Especificamente em relação à vida, entende-se que se trata de bem jurídico disponível (assim como a integridade física). No entanto, alguns cuidados especiais são necessários, principalmente em relação à verificação da capacidade do consenciente, que geralmente estará em situação de vulnerabilidade. Tendo em vista a existência do crime de participação em suicídio no ordenamento jurídico-criminal pátrio, a princípio, o consentimento somente será considerado eficaz para a ortotanásia. Nas demais hipóteses, não poderá produzir efeitos.

10 - Imprescindível que todos os requisitos do consentimento sejam respeitados. Além da necessidade do bem jurídico ser disponível, devem ser observados os critérios relativos: à pessoa, que deve ser capaz; à sua forma, devendo a manifestação seguir a teoria intermediária; ao objeto, o qual compreende a ação e o resultado; bem como ao seu momento, sendo a revogação possível a qualquer tempo.

11 - Os vícios de vontade (erro, fraude e coação) afastam a aplicação do instituto do consentimento do ofendido. Lembre-se: no erro e na fraude deve-se considerar o grau de limitação do efetivo exercício de autonomia pelo consenciente (para que se verifique se são penalmente relevantes).

12 - As diversas tipologias são construções doutrinárias importantes, as quais facilitam não apenas o estudo teórico do instituto do consentimento do ofendido, mas também a sua aplicação, proporcionando a correta adequação ao caso concreto.

13 - O consentimento não deve ser confundido com a autocolocação em perigo da vítima. Haverá autocolocação em risco quando o indivíduo praticar condutas criadoras de um perigo a si mesmo ou ao se expor a um perigo causado por terceiro, ao passo que existirá consentimento do ofendido se a pessoa se expuser conscientemente ao perigo causado única e exclusivamente pelo terceiro. 
14 - O direito penal comparado demonstra que o Brasil caminha muito lentamente em relação ao instituto do consentimento do ofendido. Isso porque, diferentemente dos outros ordenamentos jurídicos (principalmente em relação à Parte Geral dos Códigos italiano, português, costa-riquenho e mexicano), no caso pátrio inexiste qualquer previsão quanto à possibilidade do consentimento. Mesmo no caso da Alemanha ou da Espanha, que também não dispõem nada na Parte Geral do seu Código, o Brasil demonstra estar menos desenvolvido em relação ao tema, tendo em vista que nos referidos países europeus existe larga aplicação jurisprudencial do instituto (e do acordo, prevalecendo a teoria dualista).

15 - O nosso ordenamento possui diversas figuras penais nas quais o consentimento faz parte de sua estrutura típica. No entanto, tais previsões não são suficientes, havendo ainda diversos crimes relacionados ao tema sem qualquer disposição legal pertinente. Nesse sentido, em razão da postura tradicional positivista dominante, importante seria a introdução do consentimento como instituto da Parte Geral do nosso Código, a fim de solucionar de maneira mais efetiva o problema, respeitando o poder de autodeterminação das pessoas (decorrente do princípio da dignidade humana) e de liberdade de ação.

16 - Deve-se considerar, neste caso, a necessidade de detalhar os principais requisitos, quais sejam, natureza jurídica, objeto (bem jurídico disponível), modo de expressão, possibilidade de revogação e capacidade - tal como o exemplo português. Destaca-se especialmente a questão da capacidade, cuja doutrina e o direito comparado demonstram enorme diversidade de posicionamentos - o que também dificulta a aplicação do instituto. Assim, sugere-se a indicação de marco etário, a fim de facilitar a aplicação do instituto.

17 - Em que pese tal postura, nada impede a imediata aplicação do instituto, adotando-se o funcionalismo. Assim, o consentimento deve ser entendido como um dos critérios da imputação objetiva. Nesse sentido, primeiramente, deve-se fazer uma análise normativa objetiva e, num segundo momento, se for o caso, deve-se indagar a respeito do aspecto subjetivo.

18 - No que diz respeito à utilização da expressão "bons costumes", utilizada em outros ordenamentos jurídicos como parâmetro para eficácia ou não do consentimento, considerase que se trata de expressão inadequada à realidade atual. São a dignidade humana, entendida como poder de autodeterminação, bem como a liberdade de ação os principais 
paradigmas para tal verificação. 


\section{REFERÊNCIAS}

ALVES, Geraldo Magela. Novo vocabulário jurídico. Rio de Janeiro: Roma Victor, 2006.

AMBOS, Kai; BÖHM, María Laura (coord.). Desenvolvimentos atuais das ciências criminais na Alemanha. Brasília: Gazeta Jurídica, 2013.

ANCEL, Marc. La défense sociale devant le problème de la victime. In: $R S c C$ (Revue de science criminelle et de droit pénal comparé), Paris, n. 4, p. 184, 1978.

ANDRADE, Manuel da Costa. Consentimento e acordo em direito penal: contributo para a fundamentação de um paradigma dualista. Coimbra: Coimbra, 2004.

. Consentimento em direito penal médico: o consentimento presumido. In: Revista Portuguesa de Ciência Criminal, Coimbra, v. 14, n. 1-2, p. 117-148, 2004.

A vítima e o problema criminal. In: Boletim da Faculdade de Direito, Coimbra, $\mathrm{n}$. 31, p. 195-447, 1980.

ASÚA, Luis Jiménez de. Tratado de derecho penal. 5. ed. Buenos Aires: Losada, 1992.

BECCARIA, Cesare. Dos delitos e das penas. Trad. Torrieri Magalhães. São Paulo: Hemus, 1983.

BECK, Ulrich. Sociedade de risco: rumo a uma outra modernidade. Trad. Sebastião Nascimento. São Paulo: Editora 34, 2010.

BITENCOURT, Cezar Roberto. Tratado de direito penal. São Paulo: Saraiva, 2013. parte geral 1.

BITTENCOURT, Edgard de Moura. Vitimologia como ciência. Revista Brasileira de Criminologia e Direito Penal, Rio de Janeiro, a. 1, n. 1, p. 143-146, 1963.

Vítima. São Paulo: Universitária de Direito, 1978.

BORGES, Roxana Cardoso Brasileiro. Direitos da personalidade e autonomia privada. 2. ed. São Paulo: Saraiva, 2007.

BOTTINI, Pierpaolo Cruz. Crimes de perigo abstrato e princípio da precaução na sociedade de risco. 3. ed. São Paulo: Revista dos Tribunais, 2013.

A confusa exegese do princípio da insignificância. In: RASCOVSKI, Luiz (coord.). Temas relevantes de direito penal e processual penal. São Paulo: Saraiva, 2012. p. 237252.

BRAVO, Otávio. O consentimento do ofendido na teoria do direito e na teoria da pena. $O$ direito em movimento, Revista do Instituto Capixaba de Estudos, Vitória, n. 2, p. 195-216, 2000.

CÂMARA, Guilherme Costa. Programa de política criminal: orientado para a vítima de crime. São Paulo: Revista dos Tribunais/Coimbra: Coimbra, 2008.

CAMARGO, Antonio Luis Chaves. Imputação objetiva e direito penal brasileiro. São Paulo: Cultural Paulista, 2002.

CANCIO MELIÁ, Manuel. Conducta de la víctima e imputación objetiva en derecho: 
estudio sobre los ámbitos de responsabilidad de víctima y autor en actividades arriesgadas. Barcelona: Bosh, 1998.

CAPEZ, Fernando. Consentimento do ofendido e violência desportiva: reflexos à luz da teoria da imputação objetiva. São Paulo: Saraiva, 2003.

CASTRO, José Nieves Luna. Los derechos de la víctima en el processo penal contemporáneo: el caso del México en el derecho comparado. Cuadernos de política criminal, Madrid, n. 89, p. 181-223, 2006.

CHAVES, Virgínia Márcia Nepomuceno. A participação da vítima no crime. MPMG jurídico, Belo Horizonte, a. 2, n. 7, p. 47-49, 2006.

CLOTET, Joaquim. Bioética: uma aproximação. Porto Alegre: EDIPUCRS, 2003.

CÓDIGO Penal alemão. Versão em espanhol. Trad. de Claudia López Diaz. Disponível em: «http://www.juareztavares.com/textos/leis/cp_de_es.pdf». Acesso em 28 mar. 2013.

DEL RE, Michele C.. Il consenso dela vittima. In: FERRACUTI, Franco. L'intervento medico e psicológico sul testimone, sull'imputato e sul condannato. Milano: Giuffrè, 1990. p. 353-366.

DERZI, Misabel de Abreu Machado. Direito tributário, direito penal e tipo. 2. ed. São Paulo: Revista dos Tribunais, 2007.

DIAS, Jorge de Figueiredo. Direito penal: parte geral. 2. ed. ( $1^{\mathrm{a}}$ ed. brasileira). Portugal: Coimbra/São Paulo: Revista dos Tribunais, 2007. t. 1.

. Temas básicos da doutrina penal - sobre os fundamentos da doutrina penal, sobre a doutrina geral do crime. Coimbra: Coimbra, 2001.

DÍAZ-ARANDA, Enrique. El consentimiento en el derecho penal mexicano. Anuario de Derecho Penal y Ciencias Penales, Madrid, v. 49, n. 3, p. 1005-1020, 1996.

DINIZ, Débora. Quando a morte é um ato de cuidado. In: Nos limites da vida: aborto, clonagem humana e eutanásia sob a perspectiva dos direitos humanos. Rio de Janeiro: Lumen Juris, 2007.

ECO, Umberto. Como se faz uma tese. 14. ed. São Paulo: Perspectiva, 1996.

ESER, Albin. Sobre la exaltación del bien jurídico a costa de la victima. Trad. Manuel Cancio Meliá. Bogotá: Universidad Externado de Colombia, 1998.

FARIA, Antônio Bento de. Annotações théorico-praticas ao Código Penal do Brazil. Rio de Janeiro: Francisco Alves, 1913. t. 1.

FERNÁNDEZ, Gonzalo D.. Bien jurídico y sistema del delito. Buenos Aires: Julio César Faira, 2004.

FERREIRA, Aurélio Buarque de Holanda. Aurélio: o dicionário da língua portuguesa. Curitiba: Positivo, 2008.

FREITAS JR., Antonio Rodrigues de. Tráfico de pessoas e repressão ao crime organizado. Revista Internacional de Direito e Cidadania. Disponível em: «http://www.iedc.org.br/REID/ arquivos/00000086-01.pdf». Acesso em: 23 abr. 2013. 
GRECO, Alessandra Orcesi Pedro; RASSI, João Daniel. Crimes contra a dignidade sexual. 2. ed. São Paulo: Atlas, 2011.

. A autocolocação da vítima em risco. São Paulo: Revista dos Tribunais, 2004.

- Vítima, consentimento e imputação objetiva. Revista da Associação Brasileira de Professores de Ciências Penais, São Paulo, v. 1, p. 185-197, 2004.

GRECO FILHO, Vicente; RASSI, João Daniel. Lei de drogas anotada. 3. ed. São Paulo: Saraiva, 2009.

Aula proferida em 20 de março de 2013 ao curso de Pós Graduação do Departamento de Direito Penal da Faculdade de Direito da Universidade de São Paulo.

Crime: essência e técnica. In: Boletim do Instituto Manoel Pedro Pimentel, São Paulo, v. 5, n. 21, p. 11-12, 2002.

Imputação objetiva: o que é isso? Disponível em: «http://www.ibccrim.org.br/site/artigos/capa.php?jur_id=972». Acesso em 02 jun. 2011.

. Tipicidade, bem jurídico e lavagem de valores. In: COSTA, José de Faria; SILVA, Marco Antonio Marques da (coord.). Direito penal especial, processo penal e direitos fundamentais - visão luso-brasileira. São Paulo: Quartier Latin, 2006. p. 152-153.

; GRECO, Alessandra Orcesi Pedro; RASSI, João Daniel. Direito penal e processual penal eleitoral: comentários aos crimes da Lei n. 4.737 (Código eleitoral), Lei complementar 64/90 (inegibilidade), e Lei n. 9.504/97 (eleições), no prelo.

GRISPIGNI, Filippo. La natura giuridica del consenso del'offeso. Modena: Modenese, 1922.

Consenso dell'offeso. Roma: Athenaeum, 1924.

HABERMAS, Jürgen. A inclusão do outro: estudos de teoria política. 2. ed. São Paulo: Loyola, 2004.

HASSEMER, Winfried. Consideraciones sobre a la víctima del delito. Anuario de Derecho Penal y Ciencias Penales, Madrid, v. 43, fasc. 1, p. 241-259, jan./abr. 1990.

; LARRAURI, Elena. Justificación material y justificación procedimental en el derecho penal. Madrid: Tecnos, 1997.

HEFENDEHL, Roland. O bem jurídico como a pedra angular da norma penal. In: GRECO, Luis; LARA, Fernanda (org.). O bem jurídico como limitação do poder estatal de incriminar? Rio de Janeiro: Lumen Juris, 2011, p. 57-75.

HENTIG, Hans. The criminal and his victims. New Haven: Yale University Press, 1948.

HUNGRIA, Nélson. Comentários ao código penal. Rio de Janeiro: Forense, 1956.

. Fraude penal. Rio de Janeiro: A. Coelho Branco Filho, 1934.

JAKOBS, Günther. A imputação objetiva no direito penal. Trad. André Luís Callegari. São Paulo: Revista dos Tribunais, 2000.

Suicídio, eutanásia e direito penal. Barueri: Manole, 2003.

JESCHECK, Hans-Heinrich. Tratado de derecho penal. Trad. Miguel Olmedo Cardenete. 5. ed. Granada: Colmares, 2002.

LOBATO, José Danilo Tavares. O meio ambiente como bem jurídico e as dificuldades de 
sua tutela pelo direito penal. Revista Liberdades, São Paulo, n. 5, p. 54-84, set./dez. 2010.

LÓPEZ BARJA DE QUIROGA, Jacobo. El consentimiento en el derecho penal. Madrid: Dykinson, 1999.

LÓPEZ DÍAZ, Claudia. Introducción a la imputación objetiva. Colombia: Universidad Externado de Colombia - Centro de Investigaciones de Derecho Penal y Filosofía del Derecho, 2000. (Colección de Estudios nº 5).

LUCA, Heloisa Merotto de. O consentimento do ofendido à luz da teoria da imputação objetiva. Revista da Faculdade de Direito da Universidade de São Paulo, São Paulo, v. 100, p. 739-815, 2005.

LUISI, Luiz. Os princípios constitucionais penais. 2. ed. Porto Alegre: Fabris, 2003.

MAÑAS, Carlos Vico. Princípio da insignificância: excludente da tipicidade ou da ilicitude? In: SUANNES, Adauto Alonso Silvinho et al. Escritos em homenagem a Alberto Silva Franco. São Paulo: Revista dos Tribunais, 2003. p. 143-150.

MARINHO, Renato Silvestre. Princípio da autorresponsabilidade no direito penal. Dissertação de mestrado - Universidade de São Paulo, São Paulo, 2013.

MARQUES, José Frederico. Curso de direito penal. São Paulo: Saraiva, 1956. v. 2.

MARTEL, Letícia de Campos Velho. Direitos fundamentais indisponíveis: os limites e os padrões do consentimento para a autolimitação do direito fundamental à vida. Dissertação de mestrado - Universidade do Estado do Rio de Janeiro, Rio de Janeiro, 2010.

MAYR, Eduardo [org.]; KOVOSKI, Ester; PIEDADE, Heitor Júnior. Vitimologia em debate. Rio de Janeiro: Forense, 1990.

MELLO, Maria Chaves de. Dicionário jurídico inglês-português português-inglês. 8. ed. São Paulo: Método, 2006.

MESA, Marcelo J. López; CESANO, José Daniel. Antijuridicidad y causas de justificación: contribuciones a su estudio desde las ópticas civil y penal. Buenos Aires: Editorial B de F, 2010.

MIRABETE, Julio Fabrini; FABRINI, Renato N.. Manual de direito penal. 26. ed. São Paulo: Atlas, 2010. v. 1.

MIR PUIG, Santiago. Derecho penal: parte general. 9. ed. Barcelona: Reppertor, 2011.

NUCCI, Guilherme de Souza. Manual de direito penal. 7. ed. São Paulo: Revista dos Tribunais, 2011.

NUNES, Rizzatto. Manual da monografia jurídica: como se faz: uma monografia, uma dissertação, uma tese. 7. ed. São Paulo: Saraiva, 2009.

OLIVEIRA, Ana Sofia Schmidt de. A vítima e o direito penal: uma abordagem do movimento vitimológico e de seu impacto no direito penal. São Paulo: Revista dos Tribunais, 1999.

PASCHOAL, Janaina Conceição. Constituição, criminalização e direito penal mínimo. São Paulo: Revista dos Tribunais, 2003.

PASCHOAL, Nohara. O estupro: uma perspectiva vitimológica. Dissertação de mestrado Universidade de São Paulo, São Paulo, 2014.

PÉREZ LUÑO, Antonio Enrique. Derechos humanos, Estado de Derecho e Constitución. 
8. ed. Madrid: Tecnos, 2003.

PIERANGELLI, José Henrique. O consentimento do ofendido na teoria do delito. São Paulo: Revista dos Tribunais, 1989.

PITHAN, Lívia Haygert. O consentimento informado como exigência ética e jurídica. In: CLOTET, Joaquim; FEIJÓ, Anamaria; OLIVEIRA, Marília Gerhardt de (coord.). Bioética: uma visão panorâmica. Porto Alegre: EDIPUCRS, 2011. p.135-152.

POLAINO-ORTS, Miguel. Alegato en favor de un tratamiento jurídico-penal unitario para los casos de acuerdo y consentimiento como causas de atipicidad. Cuadernos de Política Criminal - CESEJ, Madrid, n. 82, p. 163-204, 2004.

PRADO, Luiz Regis. Curso de direito penal brasileiro. 6. ed. São Paulo: Revista dos Tribunais, 2006. v. 1.

RIZ, Roland. Il consenso dell'avente diritto. Padova: Dott. Antonio Milani, 1979.

RODRIGUES, Thaís de Camargo. O tráfico internacional de pessoas para fim de exploração sexual e a questão do consentimento. Dissertação de mestrado - Universidade de São Paulo, São Paulo, 2012.

ROXIN, Claus. Derecho penal - parte general. 2. ed. Trad. Diego-Manuel Luzón Peña, Miguel Díaz y García Conlledo e Javier de Vicente Remesal. Madrid: Civitas, 1997. t. 1.

Sobre o recente debate em torno do bem jurídico. In: GRECO, Luis; LARA, Fernanda (org.). O bem jurídico como limitação do poder estatal de incriminar? Rio de Janeiro: Lumen Juris, 2011, p. 179-209.

. Novos estudos de direito penal. Trad. Luís Greco, Augusto Assis, Alaor Leite e Marina Coelho. São Paulo: Marcial Pons, 2014.

. Sobre a discussão acerca da heterocolocação em perigo consentida. In: LEITE, Alaor (org.). Novos estudos de direito penal. Trad. Luís Greco, Augusto Assis, Alaor Leite e Marina Coelho. São Paulo: Marcial Pons, 2014, p. 129-151.

SANTORO, Luciano de Freitas. Morte digna: o direito do paciente terminal. Curitiba: Juruá, 2010.

SCHÜNEMANN, Bernd. Introducción al razonamiento sistemático en derecho penal. In: . El sistema moderno del derecho penal: cuestiones fundamentales. Buenos Aires: B de F, 2012, p. 1-78.

SEGURA GARCÍA, María José. El consentimiento del titular del bien jurídico en derecho penal: naturaleza y eficacia. Valencia: Tirant lo Blanch, 2000.

SILVA, De Plácido e. Vocabulário jurídico. Rio de Janeiro: Forense, 1996.

SILVA, Roberto Baptista Dias da. Uma visão constitucional da eutanásia. Tese de doutorado - Pontifícia Universidade Católica, São Paulo, 2007.

SILVA SÁNCHEZ, Jesús-María. A expansão do direito penal: aspectos da política criminal nas sociedades pós-industriais. 2. ed. São Paulo: Revista dos Tribunais, 2011.

SIQUEIRA, Galdino. Tratado de direito penal. Rio de Janeiro: José Konfino, 1947. (parte geral).

TRINDADE, André Fernando dos Reis. Para entender Luhmann e o direito como sistema autopoiético. Porto Alegre: Livraria do Advogado, 2008. 
ZAFFARONI, Eugenio Raúl; BATISTA, Nilo. Direito penal brasileiro. 2. ed. Rio de Janeiro: Renavan, 2010. v. 2. 